\title{
Chapter 8 \\ Access to Early Generation Seed: Obstacles for Delivery of Climate-Smart Varieties
}

\author{
Laura K. Cramer
}

\subsection{Introduction}

As anthropogenic climate change alters environments across eastern and southern Africa (ESA), farmers will need new crop varieties to counter predicted drops in yields and address new disease threats (Challinor et al. 2016; Spielman and Smale 2017). To help mitigate against potential declines in food security, farmers will need access to crop varieties that perform better under water stress; are shorter-maturing and therefore better adapted to changing rainfall patterns; and are more resistant to new pests and diseases. For one crop_common bean (Phaseolus vulgaris L.) — climate models predict that by the 2020s approximately 3.8 million ha of suitable area in Africa would benefit from a bean seed with improved drought tolerance (Buruchara et al. 2011). Research is also beginning to show that climate change is affecting the nutritional value of crops (Myers et al. 2017), suggesting that, to combat malnutrition, farmers must have access to varieties that maintain nutrient levels under higher levels of atmospheric carbon dioxide.

Agricultural researchers and plant breeders have been producing improved seeds in ESA for many decades, but adoption rates remain low (Table 8.1). Despite large investments in breeding, many varieties have never been commercially disseminated (Walker and Alwang 2015). In addition, the length of the breeding, dissemination and adoption (BDA) cycle for some varieties of crops can be as long as 30 years (Challinor et al. 2016). Given the rapid pace of climate change, this cycle is too long to meet the needs of farmers. The process needs to be shortened so that improved

\footnotetext{
L. K. Cramer $(\triangle)$

International Center for Tropical Agriculture (CIAT), Nairobi, Kenya

CGIAR Research Program on Climate Change, Agriculture and Food Security (CCAFS), Wageningen, The Netherlands

e-mail:1.cramer@cgiar.org
} 
Table 8.1 Adoption of modern varieties of bean in Sub-Saharan Africa in 2009

\begin{tabular}{l|c}
\hline Country & Area planted with modern varieties of beans (\%) \\
\hline Burundi & 8.1 \\
\hline DR Congo & 16.1 \\
\hline Ethiopia & 43.7 \\
\hline Malawi & 54.6 \\
\hline Mozambique & 13.5 \\
\hline Rwanda & 19.0 \\
\hline Tanzania & 45.8 \\
\hline Uganda & 31.0 \\
\hline Zambia & 9.5
\end{tabular}

Source: Muthoni and Andrade (2015)

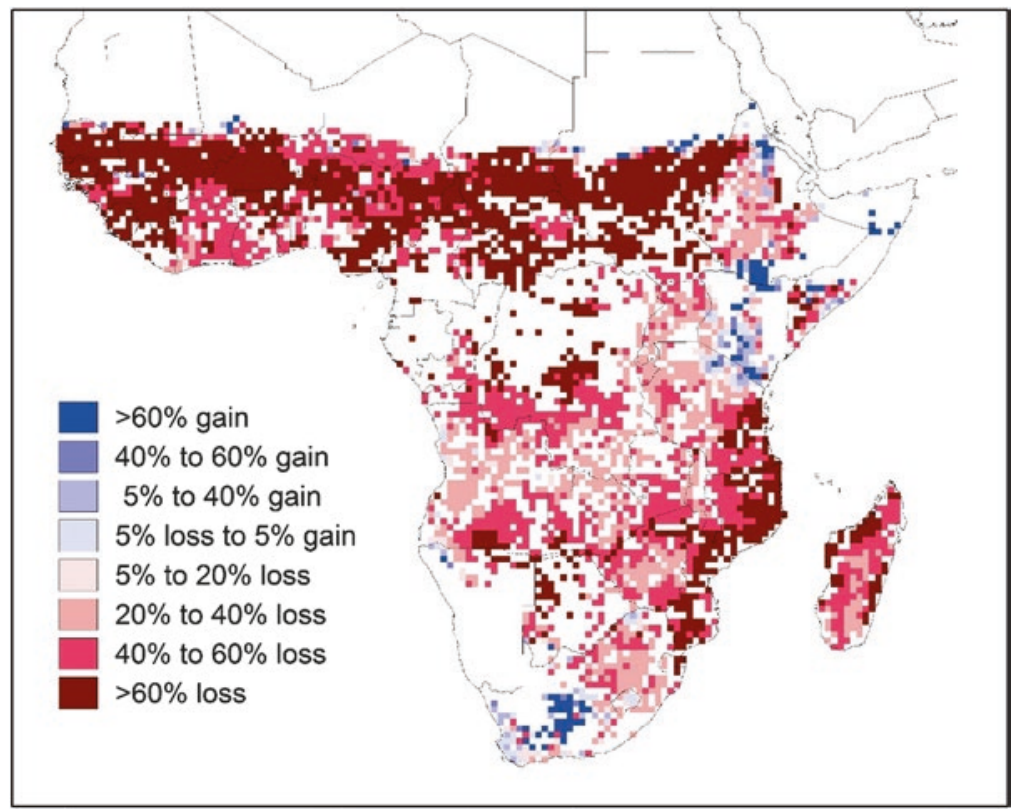

Fig. 8.1 Projected changes in dry bean production: percentage change in production by 2050s, assuming RCP8.5 (high-end emissions), in relation to the mean production of 1971-2000. (Source: Ramirez-Villegas and Thornton 2015)

varieties can reach farmers in a timelier manner (Atlin et al. 2017). Although large areas of Africa are expected to become climatically unsuitable for bean cultivation, certain areas of Kenya are expected to shift in the opposite direction, becoming more suitable (Fig. 8.1). These areas will become increasingly important for bean production as the climate continues to change. Given that beans are a key source of 
protein and micronutrients in the Kenyan diet, it is critical that new varieties are made available.

The research-for-development community has in recent years been paying increased attention to seed systems (Scoones and Thompson 2011). Initiatives such as the Alliance for a Green Revolution in Africa (AGRA) are working toward improving crop-seed systems, and approaches such as Integrated Seed Sector Development (ISSD) are being created to help in such efforts (Louwaars and de Boef 2012). But obstacles remain. In order for the private sector to play a key role in the dissemination of climate-adapted varieties, major bottlenecks in access to EGS need to be reduced. Such bottlenecks include complicated and disparate licensing agreements among the various regional genetics suppliers; lack of availability of sufficient breeder seed from licensors; and lack of financial resources, technical knowhow and infrastructure to maintain EGS. National governments, international institutions and universities need to work together with seed suppliers to harmonize regulations and streamline access to EGS for the benefit of small-scale farmers. This chapter will briefly explain the structure of seed systems and then address the bottleneck of EGS availability. It will do so through the presentation of two contrasting case studies involving access to EGS in Kenya. The chapter concludes with lessons from the case studies and implications for policy.

\subsection{Brief Overview of Seed Systems and Related Interventions}

Crop-seed systems in ESA involve a variety of sources and both formal and informal actors. According to McGuire and Sperling (2016), small-scale farmers obtain their seeds from local markets $(51 \%)$, their own saved stocks $(31 \%)$, friends and relatives (9\%), agro-dealers (2\%) and other sources. Supply systems vary depending on the type of crop, with hybridized row crops, cereals and legumes being of greater interest to the private seed sector compared to vegetatively propagated species such as sweet potato and cassava (see Parker et al. in this volume). A generic, much-simplified schematic of a seed system is presented in Fig. 8.2 for illustrative purposes, highlighting the position of EGS in the pathway.

National agricultural research services (NARSs), together with international agricultural research centers (IARCs) and other partners, have spent many decades breeding new crop varieties (see the top left portion of Fig. 8.1) (Walker and Alwang 2015). For many years non-governmental organizations (NGOs) and government extension services have distributed seeds directly to farmers or conducted seed and voucher fairs (Sperling and McGuire 2010). In recent years development partners have been providing funding for broader seed-sector development, including AGRA's support for capacity-building of agro-dealers (marketing and distribution column in Fig. 8.1) and local commercial seed companies 


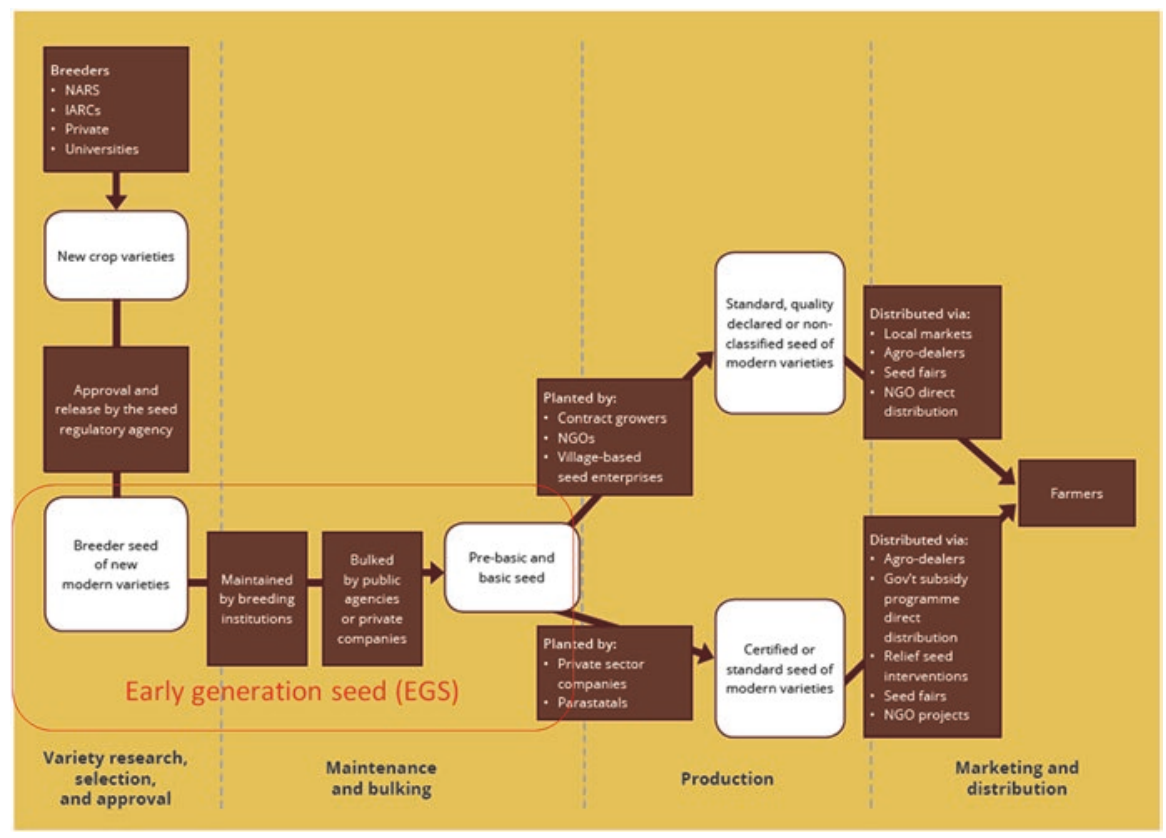

Fig. 8.2 Generic schematic diagram of a seed system. (Source: AgriExperience 2016)

(production column of Fig. 8.1) (McGuire and Sperling 2016). This moves the interventions from the top left along the supply chain toward the bottom center of the diagram. However, historically there has been a disconnect in the interventions: breeding activities from the top left often stopped at the release of a new variety, and seed distribution initiatives often promoted varieties that had been on the market for a long time. This caused a gap to develop around the issue of EGS for newly released varieties.

EGS — which encompasses breeder seed, pre-basic and basic seed-is the critical connection between breeding activities and the eventual production and distribution of varieties to farmers. The inattention paid to this part of the African food crop-seed sector as it has expanded in the last 20 years has created a major constraint within seed systems (EGS Africa Communiqué 2016). Recently a number of country case studies were published along with a communiqué setting forth principles for commercial and sustainable EGS supply (see Box 8.1). The following two case studies highlight the need for national governments to adopt clearer seed-sector policies abiding by these guiding principles, and for actors along the seed value chain to work in an integrated manner. 


\section{Box 8.1 Principles of Commercial and Sustainable EGS Supply (Source: Adapted from EGS Africa Communiqué 2016)}

1. EGS interventions should be guided by the seed value chain, starting with farmer use of - and willingness to pay for-new, improved varieties.

2. EGS operations should include hybrid, self-pollinated and vegetatively propagated crops; cover formal, intermediary and informal seed systems; and engage public, private and community-based partners.

3. EGS supply should cater to different seed systems (not just the formal system).

4. Effective EGS supply should be part of enhanced seed-value-chain management and integration.

5. An assessment of the division of responsibilities for financing and supply of EGS should be undertaken, with specific consideration of publicprivate partnerships for open-pollinated and vegetatively propagated crops.

6. National agricultural research organizations (NAROs) are and should remain responsible for the production of breeder seed for improved varieties developed by publicly-financed crop-improvement programmes.

7. A gradual withdrawal of Consultative Group for International Agricultural Research (CGIAR) programmes in direct involvement with EGS production is recommended to move toward a more sustainable seed sector.

8. Research organizations and their breeders should partner in the maintenance of breeder seed so as to keep their priority focus on further crop improvement.

9. Several aspects of regional seed-trade harmonization efforts are relevant to EGS supply, including facilitating movement of EGS supply across borders.

10. Donors should transition from direct interventions in the seed value chain to strengthening public and/or private-sector capacity in EGS supply.

\subsection{EGS Case Studies}

The case studies presented in this chapter were developed through key informant interviews with a small, local seed company based in Kenya, correspondence with a university bean breeder, and a review of documents provided by the company and found in online searches. Names of some individuals and entities have been omitted to maintain the anonymity of those consulted. The case studies involve the same seed company interacting with two different universities. The examples are contrasting: one is a successful example of EGS sharing, and the other is an example of how the lack of EGS access can hinder commercialization of a new variety. 


\subsubsection{Case Study 1: Successful Partnerships for Highland Bean Varieties}

The maize lethal necrosis (MLN) disease was first reported in Kenya in 2011 and caused significant losses to households (FSNWG 2013). According to de Groote et al. (2016), an estimated 500,000 mt of maize were lost in 2013, an amount valued at US\$180 million and equivalent to $22 \%$ of average annual production. As the disease spread in the highlands of the Rift Valley, Kenya's agricultural extension service recommended that small-scale farmers plant crops other than maize to avoid infection and spread of the disease. Given that the main staple crops in the Kenyan diet are maize and beans, beans were a logical choice for farmers to plant. Common beans have not been grown historically in the highland areas because average temperatures were too low, ${ }^{1}$ but in the last two decades rising average temperatures have made it possible to grow beans in these locations (MoALF 2016). Beans grown at high elevation, however, can be more vulnerable to diseases such as angular leaf spot, rust, common bacterial blight and root rot (Wagara and Kimani 2007).

Egerton University, in collaboration with the International Center for Tropical Agriculture (CIAT), developed and was starting to commercialize medium- to highaltitude bean varieties with disease resistance, and three varieties (Chelalang, Ciankui and Tasha) were deemed suitable for the situation arising from the MLN crisis. Between 2011 and 2014, the university partnered with several local seed companies. The involved parties signed contracts through which the university sold breeder seed (a type of EGS) to the seed companies, who received non-exclusive rights for multiplication, upscaling and commercialization. With funding received from AGRA in 2014, the university promoted and marketed the new varieties to help farmers learn about them. One variety in particular, Chelalang, has since been adopted by farmers in the highlands affected by MLN and is growing in popularity in the Rift Valley region. In 2017, Chelalang was included in an input-supply programme of the Kenyan government, the Kenya Cereal Enhancement Programme, through which 30,000 farmers each received enough seed to plant half an acre with that variety. A total of $300 \mathrm{mt}$ of Chelalang seed was distributed prior to the long rainy season, stretching from March to May (pers. comm.).

With the spread of MLN disease creating an urgent need for action, the university and the seed companies quickly reached an agreement on the provision of the necessary breeder (EGS) seed, which was readily available in sufficient quantities. The cost for one ton of breeder seed was approximately US\$2900. Egerton did not charge the companies a licensing fee, and under the agreement the companies pay a $5 \%$ royalty on gross sales to the university. The marketing efforts funded by development partners (received after the licensing agreements had been signed) helped raise awareness among farmers and stimulate demand. Using Fig. 8.1 as an analytical framework for assessment of this case study, the breeding had already

${ }^{1}$ Common bean is suited to optimal average daily temperatures of $20-25{ }^{\circ} \mathrm{C}$, and below $15{ }^{\circ} \mathrm{C}$ seeds germinate poorly (De Ron et al. 2016). 
been done in anticipation of future needs, the early generation breeder seed was in stock at the university, and the university quickly shared it through an agreement with local seed companies. The breeder was eager to see it reaching farmers and helped align the public good with commercial interests. Because they had previously worked together, there was an adequate level of trust between the university breeder and the seed companies that the contracts would be honored and the correct royalties paid. The companies were then able to bulk up the breeder seed and obtain all the necessary approvals from the Kenya Plant Health Inspectorate Service (KEPHIS) to get certified seed to market and thus available to the farmers who needed an alternative to maize. In this case, there was sufficient trust between the actors and smooth coordination for contract establishment, and EGS availability and access were not a hurdle.

\subsubsection{Case Study 2: The EGS Hurdle for a Bean Variety High in Iron and Zinc}

The second case study, by contrast, illustrates the difficulties that often arise. Two NGOs serving small-scale farmers were interested in procuring a bean variety high in iron and zinc that had been developed by a breeder at a local university using breeding lines provided by CIAT. This variety was developed through a project aimed at increasing the micronutrient quality of beans (CIAT 2005). The variety had been registered by the breeder in the Kenya seed catalogue of 2012, but it was not yet commercially available. One of the NGOs requested a sample of the seeds from the university breeder to use in demonstration plots, and the other NGO placed an advertisement in a national daily newspaper tendering for seed of a bean variety with the required characteristics. The first NGO also asked a seed company (one of the same companies involved in the project described in the first case study) if seeds of bean varieties with high iron and zinc bioavailability were available. The seed company, realizing a market need due to both the inquiry and the newspaper advertisement, made contact with the breeder at the university with the hope of paying for non-exclusive rights to commercialize the variety, which would allow the company to provide certified seed to the interested NGOs and to sell the variety in the open market.

The seed company, breeder and university office for intellectual property management went through several rounds of negotiation over the course of a year to try to reach an agreement but were unable to do so. The seed company was planning to start with production of $20 \mathrm{mt} /$ year (increasing in subsequent years as demand rose). The draft contract proposed by the university stipulated that the seed company must purchase at least $2 \mathrm{mt}$ of breeder seed every season to cover the costs of human resources, land, technical support, etc., in addition to paying an annual licensing fee. The company, however, was requesting a one-time purchase of only $50 \mathrm{~kg}$ of breeder seed. It planned to then bulk up this seed into the required amount 
of pre-basic and basic seed (see Fig. 8.1). The university also requested that the seed company carry out the production of the breeder seed on the university's behalf and then purchase it, with the cost of production subtracted from the price. This request indicated that an adequate amount of breeder seed was not available at the university. According to the university breeder, there was lack of a framework for producing certified breeder, pre-basic and basic seed for new varieties. It was assumed that breeders and/or their institutions would have the resources for this production and to support commercialization of new varieties, but in fact this is rarely the case (pers. comm.).

The agreement foundered because the seed company was unwilling to commit to buying such a large amount of seed every season and did not have the capacity to undertake the production of the breeder seed as the university was requesting. The upfront investment was considered too high for a variety that had not yet been commercialized. The total fixed cost of the stipulated $2 \mathrm{mt}$ of breeder seed per season, along with the annual licensing fees and royalties as laid out in the proposed contract, would have amounted to a cost of $33 \%$ of the seed price at current market rates for a similar bean variety, squeezing already tight profit margins for the company when production, marketing and distribution costs were factored in. This made the agreement unattractive for the company. The university was unwilling to yield to the seed company's requests for a smaller amount of breeder seed, and the seed company was unable to meet the university's purchasing requirements. A lack of an urgent focusing event, apparent unavailability of EGS for the variety in question, and low motivation for commercialization all contributed to the failure to reach an agreement.

This case study illustrates how the lack of access to EGS has prevented a needed variety from reaching farmers. The university that holds the rights to the variety was seemingly not able to provide the breeder seed requested, and the seed company could not shoulder the burden to produce and purchase an amount that was uneconomical for its needs. There was no other bean variety released in Kenya with the nutritional properties specified. As a result, the bean variety that was developed to help reduce micronutrient malnutrition remains uncommercialized and unavailable to Kenyan farmers. The university breeder reported that he has released 24 bean varieties in Kenya but that only 10 have been commercialized (pers. comm.). The university has worked with the largest seed company in Kenya and provided it with exclusive rights to other bean varieties, but there appears to be a lack of trust and understanding between the university and the smaller seed company, leading to a failure to reach an agreement.

\subsection{Possible Solutions and Implications for Development}

Development partners such as the Bill and Melinda Gates Foundation (BMGF) and United States Agency for International Development (USAID) have started paying attention to the EGS hurdle and are studying the multiple causes of the 
constraints and how to overcome them (BMGF and USAID 2015). A host of recommendations by country and crop have been proposed to help address the relevant issues, including partial or full subsidization of EGS production costs for crops such as beans. In the Kenya country report released as part of the BMGF and USAID EGS studies, one of the main bottlenecks identified in the common bean EGS supply system is "inadequate supply of breeder seed from public sector breeders" which "precludes private sector involvement in EGS production and limits EGS production overall" (Context Network 2016, p. xvii). The second case presented here illustrates this constraint. The recommendation is for a publicprivate partnership (PPP) to reduce production burdens on the public sector and costs imposed on the private sector in an effort to improve the availability of EGS for common bean (Context Network 2016). Given the existing lack of trust between actors, there is a role for a neutral broker to help bring stakeholders together and facilitate the development of such a partnership.

The Pan-Africa Bean Research Alliance (PABRA), a long-running research consortium led by CIAT, comprises hundreds of actors and is active in 31 African countries (PABRA 2018). Along with its successes in breeding, variety release and dissemination, the alliance has learned lessons about breeding and seed production. As described by Buruchara et al. (2011, p. 241), "[p]ublic sector research has to commit to producing breeder seed-as an integral part of the variety development process. There is no sense in releasing a variety (or engaging in breeding) if that variety is not set on a course for multiplication."

Getting the actors represented in the top left of Fig. 8.1 to work in harmony with other stakeholders and building trust is key to overcoming the constraints of EGS supply. Clearer seed regulation policies within national governments and their agencies on the maintenance and supply of EGS would assist in overcoming such barriers. More commercially viable licensing options, particularly in cases where one supplier has a monopoly on a variety that has high value for cultivation, would also be useful. While there is a government-recommended royalty in Kenya (3\%), this does not prevent the addition of other licensing fees and costs that drive up the expense to procure breeder seed and begin production (pers. comm.). Stronger commitment from those funding breeding programmes to take the new varieties through all the stages to commercialization (instead of stopping at release) would also help overcome the EGS hurdle.

The research-for-development community, national governments and private sector actors need to work together. New crop varieties are costly to produce, and leaving them uncommercialized is a waste of public research money (Rubyogo et al. 2010). According to Muthoni and Andrade (2015), funding for bean improvement alone at CIAT peaked at US\$13.8 million in 1990 and recently stabilized at about US $\$ 5.5$ million per year. The funders of breeding programmes should have specific goals in mind, including the ways in which any varieties that are developed will ultimately reach farmers, either through commercial processes or with public support for multiplication and distribution. Crops such as the common bean that have low multiplication rates and high transport costs require public 
research support and dissemination (BMGF and USAID 2015). The commercial sector, however, should not be overlooked. The company featured in these two case studies originally became interested in producing and selling common bean seed after the production manager realized that Kenyan farmers purchase seed at higher rates than is often assumed. They may be purchasing farmer-saved seed through the informal market, but there is also demand for higher-quality seed through the formal market (pers. comm.).

Easing the availability of EGS is now recognized as crucial to the crop-seed systems of ESA. Urgent action is required to remove the hurdles faced by privatesector companies who are ready and willing to begin commercializing new varieties and to build trust between the actors involved in breeding and commercialization. The experiences from the two cases presented here can be summarized into eight lessons:

1. Public subsidies to promote and market new varieties can encourage commercial interest.

2. Publicly funded agricultural input subsidies can kick-start the market and encourage commercial interest.

3. Access to breeder seed and multiplication rights must be at a cost low enough to attract commercial interest, and annual licensing fees should not be cost-prohibitive.

4. Universities and public breeders must invest in maintaining minimum supplies of breeder seed of promising varieties.

5. Non-exclusive rights are helpful in getting new varieties to market because they allow several small companies to sell the same variety.

6. Mandates for minimum seed production discourage commercial interest, especially for varieties that have not yet been marketed.

7. Public and private sectors ought to share the risks of initial seed multiplication and commercialization; commercial companies should not bear all of that risk.

8. Seed-sector actors should make use of focusing events (such as the MLN crisis) for public pressure to encourage successful collaboration.

Giving farmers more choices of crops and varieties through the availability of quality seeds will help enable them to better adapt to an altering environment. Because climate change will increase the spread of pests and diseases, alternative crops and resistant varieties are needed (Beebe et al. 2011). This is a critical component of climate-smart agriculture (CSA) because it allows farmers to increase their resilience through selection of appropriate varieties and boost their production by using higher-quality seeds and better-adapted varieties. If intensified production can be achieved, the third pillar of CSA—mitigation—may also be realized through reduced rates of expansion for agricultural land. 


\section{References}

AgriExperience (2016) Reaching more farmers with high quality seed for drought tolerant crops, Vuna Research Report. Vuna, Pretoria

Atlin GN, Cairns JE, Das B (2017) Rapid breeding and varietal replacement are critical to adaptation of cropping systems in the devleoping world to climate change. Glob Food Sec 12:31-37. https://doi.org/10.1016/j.gfs.2017.01.008

Beebe S, Ramirez J, Jarvis A et al (2011) Genetic improvement of common beans and the challenges of climate change. In: Yadav S et al (eds) Crop adaptation to climate change. WileyBlackwell, Oxford. https://doi.org/10.1002/9780470960929.ch25

BMGF and USAID (2015) Early generation seed study. Bill and Melinda Gates Foundation, United States Agency for International Development, Seattle, WA, USA

Buruchara R, Chirwa R, Sperling L et al (2011) Development and delivery of bean varieties in Africa: the Pan-Africa Bean Research Alliance (PABRA) model. Afr Crop Sci J 19(4):227-245

Challinor AJ, Koehler AK, Ramirez-Villegas J et al (2016) Current warming will reduce yields unless maize breeding and seed systems adapt immediately. Nat Clim Chang 6:954-958. https://doi.org/10.1038/nclimate3061

CIAT (2005) Fast tracking of nutritionally-rich bean varieties. Highlights: CIAT in Africa no. 24

Context Network (2016) Kenya early generation seed study: country report. USAID Bureau of Food Security, Washington, DC

De Groote H, Oloo F, Tongruksawattana S et al (2016) Community-survey based assessment of the geographic distribution and impact of maize lethal necrosis (MLN) disease in Kenya. Crop Prot 82:30-35. https://doi.org/10.1016/j.cropro.2015.12.003

De Ron AM, Rodiño AP, Santalla M et al (2016) Seedling emergence and phenotypic response of common bean germplasm to different temperatures under controlled conditions and in open field. Front Plant Sci 7:1087. https://doi.org/10.3389/fpls.2016.01087

EGS Africa Communiqué (2016) Communiqué on commercial and sustainable supply of early generation seed of food crops in sub-Saharan Africa. EGS Africa Communiqué, Addis Ababa Available at: http://www.issdseed.org/resource/communiqué-promoting-commercial-and-sustainable-supply-early-generation-seed-food-crops-sub

FSNWG (2013) Maize lethal necrosis disease (MLND): a snapshot. Food Security and Nutrition Working Group, FAO Sub-Regional Emergency Office for Eastern \& Central Africa

Louwaars NP, Simon de Boef W (2012) Integrated Seed Sector Development in Africa: a conceptual framework for creating coherence between practices, programs, and policies. J Crop Improv 26:39-59. https://doi.org/10.1080/15427528.2011.611277

McGuire S, Sperling L (2016) Seed systems smallholder farmers use. Food Secur 8:179-195. https://doi.org/10.1007/s12571-015-0528-8

MoALF (2016) Climate risk profile for Nakuru, Kenya County Climate Risk Profile Series. The Kenya Ministry of Agriculture, Livestock and Fisheries, Nairobi

Muthoni RA, Andrade R (2015) The performance of bean improvement programmes in subSaharan Africa from the perspectives of varietal output and adoption. In: Walker TS, Alwang $\mathrm{J}$ (eds) Crop improvement, adoption and impact of improved varieties in food crops in subSaharan Africa. CGIAR and CABI, Oxfordshire

Myers SS, Smith MR, Guth S et al (2017) Climate change and global food systems: potential impacts on food security and undernutrition. Annu Rev Public Health 38:259-277. https://doi. org/10.1146/annurev-publhealth-031816-044356

PABRA (2018) Where we work. Pan-Africa Bean Research Alliance, Nairobi, Available at: www. pabra-africa.org/where-we-work/

Ramirez-Villegas J, Thornton PK (2015) Climate change impacts on African crop production, CCAFS Working Paper no. 119. CGIAR Research Program on Climate Change, Agriculture and Food Security (CCAFS), Copenhagen Available at: www.ccafs.cgiar.org 
Rubyogo JC, Sperling L, Muthoni R et al (2010) Bean seed delivery for small farmers in sub-Saharan Africa: the power of partnerships. Soc Nat Resour 23:285-302. https://doi. org/10.1080/08941920802395297

Scoones I, Thompson J (2011) The politics of seed in Africa's green revolution: alternative narratives and competing pathways. IDS Bull 42:1-23. https://doi.org/10.1111/j.1759-5436.2011.00232.x

Sperling L, McGuire SJ (2010) Persistent myths about emergency seed aid. Food Policy 35:195201. https://doi.org/10.1016/j.foodpol.2009.12.004

Spielman DJ, Smale M (2017) Policy options to accelerate variety change among smallholder farmers in South Asia and Africa south of the Sahara. International Food Policy Research Institute, Washington, DC

Walker TS, Alwang J (2015) Crop improvement, adoption and impact of improved varieties in food crops in sub-Saharan Africa. CGIAR and CAB International, Montpellier

Wangara IN, Kimani PM (2007) Resistance of nutrient-rich bean varieties to major biotic constraints in Kenya. Afr Crop Sci Conf Proc 8:2087-2090

Open Access This chapter is licensed under the terms of the Creative Commons Attribution 4.0 International License (http://creativecommons.org/licenses/by/4.0/), which permits use, sharing, adaptation, distribution and reproduction in any medium or format, as long as you give appropriate credit to the original author(s) and the source, provide a link to the Creative Commons license and indicate if changes were made.

The images or other third party material in this chapter are included in the chapter's Creative Commons license, unless indicated otherwise in a credit line to the material. If material is not included in the chapter's Creative Commons license and your intended use is not permitted by statutory regulation or exceeds the permitted use, you will need to obtain permission directly from the copyright holder.

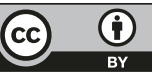

